\title{
Determination of Adenylate Nucleotides in Amphipod Gammarus fossarum by Ion-Pair Reverse Phase Liquid Chromatography: Possibilities of Positive Pressure Micro-Solid Phase Extraction
}

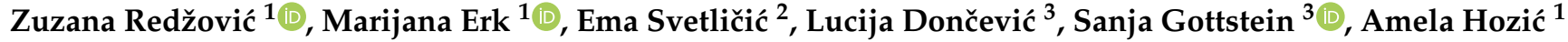 \\ and Mario Cindrić ${ }^{1, *(1)}$
}

check for

updates

Citation: Redžović, Z.; Erk, M.; Svetličić, E.; Dončević, L.; Gottstein,

S.; Hozić, A.; Cindrić, M.

Determination of Adenylate

Nucleotides in Amphipod Gammarus fossarum by Ion-Pair Reverse Phase Liquid Chromatography: Possibilities of Positive Pressure Micro-Solid Phase Extraction. Separations 2021, 8, 20. https://doi.org/10.3390/ separations 8020020

Academic Editor: Fabio Gosetti

Received: 31 December 2020

Accepted: 7 February 2021

Published: 13 February 2021

Publisher's Note: MDPI stays neutral with regard to jurisdictional claims in published maps and institutional affiliations.

Copyright: (c) 2021 by the authors. Licensee MDPI, Basel, Switzerland. This article is an open access article distributed under the terms and conditions of the Creative Commons Attribution (CC BY) license (https:/ / creativecommons.org/licenses/by/ $4.0 /)$.
1 Ruđer Bošković Institute, 10000 Zagreb, Croatia; zuzana.redzovic@irb.hr (Z.R.); marijana.erk@irb.hr (M.E.); amela.hozic@irb.hr (A.H.)

2 Faculty of Food Technology and Biotechnology, University of Zagreb, 10000 Zagreb, Croatia; esvetlicic@pbf.hr

3 Faculty of Science, University of Zagreb, 10000 Zagreb, Croatia; lucija.doncevic@gmail.com (L.D.); sanja.gottstein@biol.pmf.hr (S.G.)

* Correspondence: mario.cindric@irb.hr; Tel.: +385-992-183-280

\begin{abstract}
Adenine nucleotides—adenosine monophosphate, diphosphate, and triphosphate-are of utmost importance to all living organisms, where they play a critical role in the energy metabolism and are tied to allosteric regulation in various regulatory enzymes. Adenylate energy charge represents the precise relationship between the concentrations of adenosine monophosphate, diphosphate, and triphosphate and indicates the amount of metabolic energy available to an organism. The experimental conditions of adenylate extraction in freshwater amphipod Gammarus fossarum are reported here for the first time and are crucial for the qualitative and quantitative determination of adenylate nucleotides using efficient and sensitive ion-pair reverse phase LC. It was shown that amphipod calcified exoskeleton impeded the neutralization of homogenate. The highest adenylate yield was obtained by homogenization in perchloric acid and subsequent addition of potassium hydroxide and phosphate buffer to achieve a $\mathrm{pH}$ around 11. This method enables separation and accurate detection of adenylates. Our study provides new insight into the complexity of adenylate extraction and quantification that is crucial for the application of adenylate energy charge as a confident physiological measure of environmental stress and as a health index of G. fossarum.
\end{abstract}

Keywords: adenylate energy charge; freshwater amphipods; ecosystem monitoring; adenylate extraction; ecological friendly solutions

\section{Introduction}

Realistic environmental impact assessment is a challenging task in today's world, which is facing an increasing number of emerging contaminants every day. One of the useful approaches to assess changes in the environment is the biological monitoring or biomonitoring that systematically uses living organisms [1] such as amphipod crustaceans, giving integrative response and reflecting accumulative changes over time [2]. Amphipods are one of the most important taxonomic groups of freshwater ecosystems according to their biomass, diversity, role in functioning of ecosystems, and sensitivity to environmental disturbance $[3,4]$. The most widespread representatives of amphipods in Europe are gammarids (e.g., Gammarus fossarum) which are most often used as key bioindicators and model organisms in ecotoxicology [5]. A useful index of an organism's health is the adenylate energy charge (AEC), which is defined as the amount of metabolic energy available to an organism from the adenylate pool. It is calculated from measured concentrations of the 
three adenine nucleotides-adenosine $5^{\prime}$-triphosphate (ATP), adenosine $5^{\prime}$-diphosphate (ADP) and adenosine $5^{\prime}$-monophosphate (AMP) [6], according to the following equation:

$$
\mathrm{AEC}=\frac{\mathrm{c}(\mathrm{ATP})+\frac{1}{2} \mathrm{c}(\mathrm{ADP})}{\mathrm{c}(\mathrm{ATP})+\mathrm{c}(\mathrm{ADP})+\mathrm{c}(\mathrm{AMP})}
$$

Changes in ecological or physiological parameters can lead to fluctuations in adenylate concentrations, and in particular situations to decrease in AEC. The quantitative determination of AEC, therefore, represents one of the most important signatures of ecosystem recovery. Quantification of nucleotides using the HPLC method was previously investigated in different organisms, such as mussel [7-9], oyster [10], scallop [11], clam [12], sea urchin [13], chondrichthyans [14], worm, plant, algae, bacteria, and fungi [15]. Furthermore, nucleotides were determined in human cerebrospinal fluid [16] and hippocampal brain region [17]. A study published by Czarnecka et al. [16] introduced an effective methodology for mono-, di-, and tri-phosphonucleotides enrichment, separation, and analysis from complex physiological fluids using solid phase extraction (SPE) and HPLC. The modified SPE methodology described in the present paper is based on SPE methodology adjusted to positive pressure liquid handling system.

Regarding the measurement of adenylates in amphipod G. fossarum, the only one reported was the luminometric assay [18]. That assay has its drawbacks as only ATP can be measured directly in the tissue extract, comparing to HPLC method where ATP, ADP, AMP and other nucleotides can be measured in a single run [19]. Furthermore, the luminometric method is less selective, more time-consuming, and more expensive [20]. Accuracy of quantitative analysis of ATP using luminometric method is questionable as a side product (dehydroluciferyl-adenylate (L-AMP)) of the reactions catalyzed by luciferase was found to inhibit this enzyme [21], which could significantly influence the accuracy and the bioluminescence reaction rate [22]. Due to different biological composition and metabolic processes, adenylate distribution after extraction and analysis varies between taxa and from one tissue to another. Therefore, it is necessary to develop an analytical and extraction method that is specific for the organism of our interest. The main challenge to the development of quantitative method for adenylate analysis in G. fossarum is $\mathrm{pH}$ control affected by the exoskeleton composition of these organisms and amphipods, in general. The efficiency of adenylate extraction in different homogenization methods was investigated as well as the influence of different volumes of neutralization solution $(\mathrm{KOH})$. The most suitable method for adenylate extraction is presented in the study.

Common chromatographic methods used for nucleotide determination employed RPHPLC [7,9,14,23] or HILIC-HPLC [24] analysis. The named RP-HPLC methods contained organic modifiers, such as acetonitrile or methanol. Further on, it was stated in several publications that HILIC separation mode requires high organic content of the mobile phase $[25,26]$. However, no major differences were observed in comparative studies of nucleotide analysis using named separation techniques [24,26]. Recently, several authors highlighted the drawbacks of using organic solvents in the mobile phase, like its negative impact on human and ecosystem health or high cost of solvent waste disposal $[27,28]$. The use of organic solvent-free IP-RP-HPLC methods, such as the one introduced in the article, reduces negative impacts on the environment and human health. This work aimed to develop an organic solvent-free, sensitive, efficient, and rapid method for qualitative and quantitative IP-RP-HPLC analysis of adenylate nucleotides in amphipods. The workflow of the whole protocol from the amphipod sample preparation to the quantification of adenylates by IP-RP-HPLC is shown in Figure 1. 


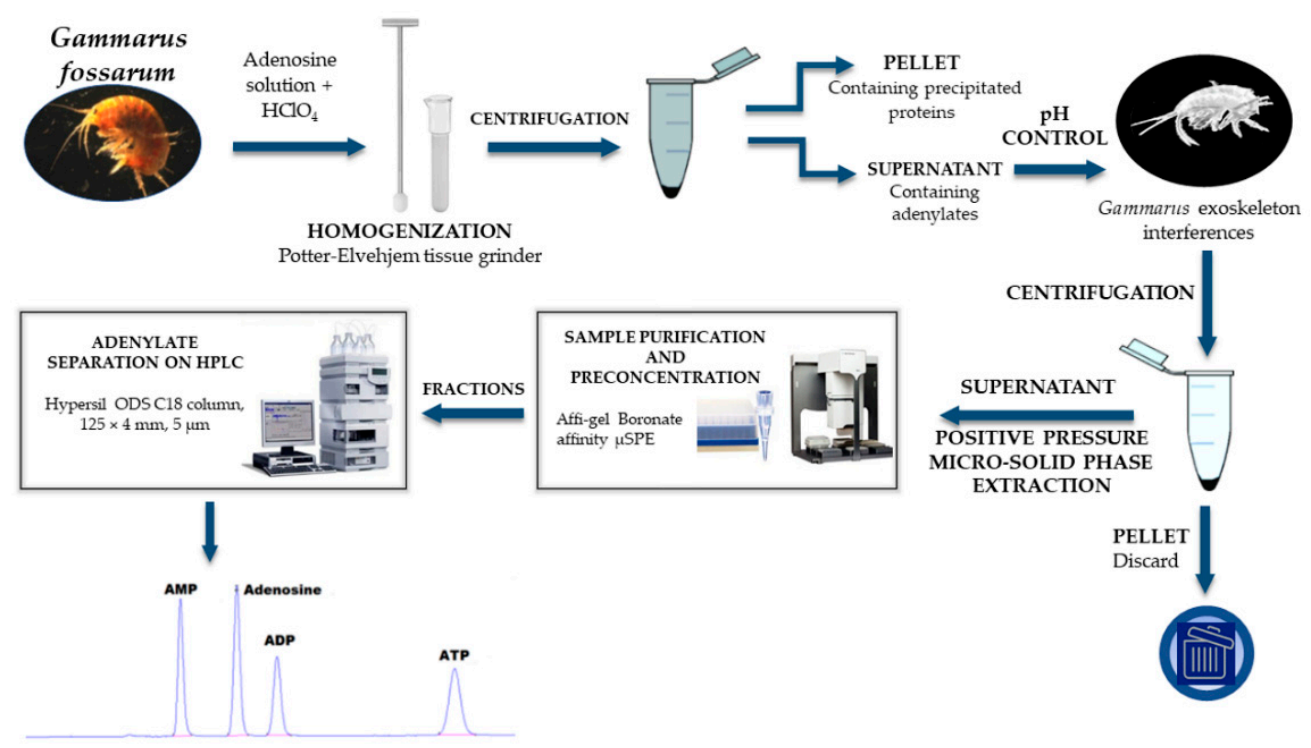

Figure 1. Schematic diagram of the workflow for extraction and determination of adenylates in G. fossarum sample.

\section{Materials and Methods}

\subsection{Chemicals}

Potassium dihydrogen phosphate, dipotassium phosphate, disodium phosphate, potassium hydroxide, potassium chloride, acetic acid, and sodium acetate were of analytical grade ( $\geq 98 \%$, Kemika, Zagreb, Croatia). Adenosine $5^{\prime}$-monophosphate (AMP), adenosine $5^{\prime}$-diphosphate (ADP), adenosine $5^{\prime}$-triphosphate (ATP), and tetrabutylammonium (TBA) hydroxide were of analytical grade ( $\geq 98 \%)$, as well as 3-(Cyclohexylamino)-1propanesulfonic acid ( $\geq 99 \%$ ), all purchased from Sigma Aldrich (St. Louis, Missouri, USA). Internal standard adenosine (ADN) was of HPLC grade ( $\geq 99 \%)$ obtained from Tokyo Chemical Industry, Japan. Perchloric acid (PCA), ACS reagent, 70\% was from Thermo Fisher Scientific (Waltham, MA, USA). Deionized $(18 \mathrm{M} \Omega \cdot \mathrm{cm})$ water, generated in-house using a Milli-Q System from Merck Millipore (Bedford, MA, USA) was used for mobile phases and solutions preparation.

\subsection{Sample Collection}

Freshwater amphipods G. fossarum Koch, 1836 (class: Malacostraca, subphylum: Crustacea, phylum: Arthropoda) were collected in spring 2018 using aquatic hand net (mesh size $500 \mu \mathrm{m}$ ). Sampling was performed in the Veliki potok Stream (the Medvednica Mountain, Croatia). In the laboratory, G. fossarum amphipods were separated from the litter and sediment, blotted with the paper tissue to remove the excess water, snap-frozen in liquid nitrogen $\left(-196^{\circ} \mathrm{C}\right)$, and subsequently stored at $-80^{\circ} \mathrm{C}$ until further analysis.

\subsection{Preparation of G. fossarum Samples and Standard Solutions}

The method was performed as described by Díaz Enrich et al. [8] with some modifications. In brief, composite samples of approximately $50 \mathrm{mg}$ of $\mathrm{G}$. fossarum were homogenized in $0.5 \mathrm{~mL}$ of $0.5 \mathrm{M}$ ice-cold perchloric acid (PCA) using a Potter-Elvehjem homogenizer (mechanical homogenization) while keeping the sample tube in ice-bath. The exact weight of the composite samples of G. fossarum was recorded immediately prior to homogenization, so the weight loss due to the freezing stage can be neglected. Samples were spiked prior to homogenization with $50.1 \mu \mathrm{L}$ of internal standard solution (300 $\mu \mathrm{M}$ ADN) prepared fresh daily by dissolving in mobile phase. Therefore, the total mass of ADN added to the sample before homogenization equals $4.01 \mu \mathrm{g}$. PCA provided acidic conditions, which enabled precipitation of proteins and inactivated enzymes that could influence the nucleotide levels. The homogenate was centrifuged in a cooled centrifuge at $4{ }^{\circ} \mathrm{C}, 16,000 \times g$ for $5 \mathrm{~min}$. After the centrifugation, a volume of $200 \mu \mathrm{L}$ of supernatant was neutralized with the addition of 
$25 \mu \mathrm{L}$ of $25 \% \mathrm{KOH}$ and $150 \mu \mathrm{L}$ of phosphate buffer $\left(0.5 \mathrm{M} \mathrm{Na}_{2} \mathrm{HPO}_{4}\right.$ and $\left.\mathrm{KH}_{2} \mathrm{PO}_{4}, \mathrm{pH}=8.2\right)$ and the final $\mathrm{pH}$ was 11 . The mixture was vortexed and allowed to form a precipitate for $30 \mathrm{~min}$ on ice. The neutralized supernatant was again centrifuged at $16,000 \times \mathrm{g}$ at $4{ }^{\circ} \mathrm{C}$ for $5 \mathrm{~min}$ and the supernatant was immediately analyzed by IP-RP-HPLC.

For calibration and method validation purposes, stock solutions of $1000 \mu \mathrm{M}$ were prepared by dissolving AMP, ADP, ATP, and ADN in mobile phase. Standard solutions were made by serial dilution to the working concentration of 10, 12, 25, 50, 100, 200, and $300 \mu \mathrm{M}$. All solutions were stored at $4{ }^{\circ} \mathrm{C}$.

\subsection{Instrumentation, HPLC Conditions, and Adenylate Quantification}

Separation of adenylates was performed by ion-pair reverse phase chromatography using HPLC system Agilent 1100 Series (St. Clara, CA, USA) equipped with a diode-array detector (DAD) and Thermo Fisher Scientific (Waltham, MA, USA) Hypersil ODS column C18 (125 mm $\times 4 \mathrm{~mm}, 5 \mu \mathrm{m}$ particle size; guard column: Hypersil ODS, $10 \times 4 \mathrm{~mm}$, $5 \mu \mathrm{m})$. The flow rate was $1 \mathrm{~mL} / \mathrm{min}$, and the wavelength was set to $260 \mathrm{~nm}$ with $80 \mathrm{~nm}$ bandwidth. An isocratic elution was used with 12 min run time. Injection volume was $3 \mu \mathrm{L}$ and the analysis was carried out at room temperature. G. fossarum samples were analyzed in duplicates. Mobile phase of $\mathrm{pH}$ about 6 and containing $150 \mathrm{mM} \mathrm{KH}{ }_{2} \mathrm{PO}_{4} / \mathrm{K}_{2} \mathrm{HPO}_{4}$, $100 \mathrm{mM} \mathrm{KCl}$, and $10 \mathrm{mM}$ tetrabutylammonium (TBA) hydroxide as an ion-pairing agent was used [16]. Nucleotides were identified based on the retention time of the standards and absorbance maxima at $260 \mathrm{~nm}$.

The concentrations of adenylates in the samples of G. fossarum were calculated using external standard calibration method. The concentrations were determined from calibration curves prepared from the known concentrations of standards (AMP, ADP, and ATP). Adenylate concentration determined in the samples of G. fossarum was calculated from peak area of given nucleotide and expressed as micromolar $(\mu \mathrm{M})$. Micromolar concentration was then converted to micromolar concentration of given nucleotide per gram of wet tissue weight. The final result was obtained by multiplying the adenylate concentration by the extraction recovery of internal standard (ADN).

\subsection{Method Validation}

Validation of the IP-RP-HPLC method was assessed through linearity range, LOD, LOQ, intra-day and inter-day precision, recovery, and stability for each nucleotide separately. Linearity was evaluated by analyzing standard solutions containing equal concentrations of AMP, ADP, ATP, and ADN: 10, 12, 25, 50, 100, 200, and $300 \mu \mathrm{M}$. Standard solutions were analyzed in triplicates. Linearity data were obtained by plotting calibration curves from mean peak area of each nucleotide against the corresponding concentration. The correlation coefficient, slope, and intercept were determined by linear least squares analysis.

LOD and LOQ were determined from a constructed calibration curve for each standard solution at a concentration range of 10 to $300 \mu \mathrm{M}$ and were calculated with the following equations $\mathrm{LOD}=3.3 \mathrm{~S}_{\mathrm{xy}} / \alpha, \mathrm{LOQ}=10 \mathrm{~S}_{\mathrm{xy}} / \alpha$, where $\mathrm{S}_{\mathrm{xy}}$ represents the standard error of the regression and $\alpha$ represents a calibration curve slope.

Precision of the method was calculated as relative standard deviation $(\mathrm{RSD}=100 \times \mathrm{SD} / \mathrm{mean})$ for seven concentration levels (10-300 $\mu \mathrm{M})$ of AMP, ADP, ATP, and ADN standards injected in triplicates on the same day (intra-day precision) and on three consecutive days (inter-day precision).

To test the extraction recovery, G. fossarum samples spiked with a known amount of ADN were used. The recovery rate (extraction efficiency) was calculated as a ratio of measured ADN concentration and a theoretical concentration added to the sample before homogenization. Recovery calculation using internal standard was chosen because ADN is not contained in G. fossarum samples and the molecule itself is highly similar to AMP, ADP, and ATP. Spiking G. fossarum samples with known amounts of analytes (AMP, ADP, and ATP) would require aliquoting the sample, which was not applicable in this case, as adenylate extraction occurs in the first step, during the homogenization of frozen G. fossarum specimens in PCA. Thus, comparison of an aliquot spiked with analytes and 
unspiked aliquot was not feasible. Because it has already been shown that homogenization method affects the adenylate yield [29], spiking samples after homogenization would not represent realistic extraction conditions.

Analyte stability under processed sample conditions was determined by comparing the nucleotide peak area in the samples that were processed and analyzed on the same day with the samples stored for seven days at $+4{ }^{\circ} \mathrm{C}$ and $-80{ }^{\circ} \mathrm{C}$.

\subsection{Positive Pressure Micro-Solid Phase Extraction (PP $\mu S P E$ )}

As the average weight of $G$. fossarum specimen was $10 \mathrm{mg}$, the availability of biological material can be a potential bottleneck in the measurements of adenylates. Thus, PP $\mu$ SPE method was developed to improve LOD and LOQ of the method. For purification and preconcentration of the homogenized sample Affi-gel Boronate affinity SPE was used (bene lab, Zagreb, Croatia). Cartridges operate under positive pressure and maximum flow-rate of $10 \mu \mathrm{L} / \mathrm{min}$. The procedure was developed for automatized high-throughput sample extraction on AssayMAP Bravo Platform (Agilent liquid handling system). For priming buffer and equilibrating buffer $100 \mathrm{mM}$ 3-[Cyclohexylamino]-1-propanesulfonic acid (CAPS) was used in the volume of $150 \mu \mathrm{L}$ and $100 \mu \mathrm{L}$, respectively. A volume of $70 \mu \mathrm{L}$ of $G$. fossarum neutralized extract $(\mathrm{pH}>11$ ) was loaded into the cartridge and eluted in two fractions. Fraction 1 was eluted with $25 \mu \mathrm{L} 0.1 \mathrm{M}$ acetic acid and fraction 2 with $25 \mu \mathrm{L}$ $0.2 \mathrm{M}$ sodium acetate. Fractions were analyzed on the same day. In joined fractions signalto-noise $(\mathrm{S} / \mathrm{N})$ ratio was improved to a factor of 10 with preserved nucleotide ratio which enables analysis of one amphipod instead of ten amphipods used in the method validation protocol in this paper. The developed PP $\mu$ SPE method has a potential to calculate accurate AEC when only a few milligrams or less of starting biological material is available in the experiment. The PP $\mu$ SPE method is not validated, but it showed AEC agreement within $\pm 10 \%$ between 10 homogenized amphipods analyzed in validated method versus a single amphipod PP $\mu$ SPE analysis. Comparison of AEC values was tested on 6 sets of samples (a single amphipod vs. 10 homogenized amphipods).

\section{Results and Discussion}

\subsection{Nucleotide IP-RP-HPLC Method Validation}

A seven-point calibration curve indicated a strong correlation between the peak area and concentrations over a total investigated range $(10-300 \mu \mathrm{M})$. The correlation coefficient $\mathrm{r}^{2}$ of the constructed calibration curve was higher than 0.999 for all standard solutions. Linearity results are shown in Table 1.

Table 1. Linearity parameters for adenylate standards determined by ion-pair RP HPLC.

\begin{tabular}{ccccccccc}
\hline Nucleotide & $\mathbf{L R}^{\mathbf{a}}(\boldsymbol{\mu M})$ & $\begin{array}{c}\text { Slope }(\boldsymbol{\alpha}) \\
\left(\boldsymbol{\mu} \mathbf{M}^{-\mathbf{1})}\right.\end{array}$ & $\mathbf{y}$-Intercept & $\mathbf{S}_{\mathbf{a}} \mathbf{b}$ & $\mathbf{S}_{\mathbf{b}} \mathbf{c}$ & $\mathbf{S}_{\mathbf{x} / \mathbf{y}} \mathbf{d}$ & $\mathbf{r}^{\mathbf{2}}$ & $\mathbf{R S S}^{\mathbf{e}}$ \\
\hline AMP & $4.41-300$ & 2.0506 & -1.3661 & 0.4755 & 0.0033 & 0.9036 & 1.000 \\
ADP & $3.04-300$ & 1.9620 & -0.7240 & 0.3142 & 0.0022 & 0.5972 & 1.000 \\
ATP & $2.67-300$ & 2.3340 & -1.8763 & 0.3274 & 0.0023 & 0.6222 & 1.000 & 1.7835 \\
ADN & $2.74-300$ & 2.5320 & -0.9110 & 0.3646 & 0.0025 & 0.6930 & 1.000 & 2.4015 \\
\hline
\end{tabular}

${ }^{a}$ Linearity range. ${ }^{b}$ Standard error of the intercept. ${ }^{c}$ Standard error of the slope. ${ }^{d}$ Standard error of the regression. ${ }^{\mathrm{e}}$ Residual sum of squares footer.

LOD/LOQ values were 1.45, 1.00, 0.88, $0.90 \mu \mathrm{M} / 4.41,3.04,2.67,2.74 \mu \mathrm{M}$ for AMP, $\mathrm{ADP}, \mathrm{ATP}$, and ADN, respectively. Intra-day and inter-day precision expressed as RSD (\%) ranged from $0.02 \%$ to $1.17 \%$ and from $0.01 \%$ to $1.69 \%$, respectively (Table 2 ), which indicated good repeatability of the method. 
Table 2. Intra-day and inter-day accuracy for AMP, ADP, ATP, and ADN standards in concentration range from 10 to $300 \mu \mathrm{M}$.

\begin{tabular}{|c|c|c|c|c|c|}
\hline \multirow{2}{*}{ Nucleotide } & \multirow{2}{*}{ Theoretical Conc. ( $\mu \mathrm{M})$} & \multicolumn{2}{|c|}{ Intra-Day } & \multicolumn{2}{|c|}{ Inter-Day } \\
\hline & & Observed Conc. $(\mu \mathrm{M})$ & RSD (\%) & Observed Conc. ( $\mu \mathrm{M})$ & RSD (\%) \\
\hline \multirow{7}{*}{ AMP } & 10 & $10.43 \pm 0.01$ & 0.10 & $10.46 \pm 0.04$ & 0.38 \\
\hline & 12 & $12.34 \pm 0.08$ & 0.65 & $12.46 \pm 0.08$ & 0.64 \\
\hline & 25 & $25.04 \pm 0.04$ & 0.16 & $25.12 \pm 0.05$ & 0.20 \\
\hline & 50 & $49.48 \pm 0.04$ & 0.08 & $49.46 \pm 0.02$ & 0.04 \\
\hline & 100 & $99.41 \pm 0.15$ & 0.15 & $99.07 \pm 0.32$ & 0.32 \\
\hline & 200 & $200.15 \pm 0.06$ & 0.03 & $200.21 \pm 0.12$ & 0.06 \\
\hline & 300 & $300.15 \pm 0.08$ & 0.03 & $300.22 \pm 0.04$ & 0.01 \\
\hline \multirow{7}{*}{ ADP } & 10 & $10.22 \pm 0.12$ & 1.17 & $10.13 \pm 0.02$ & 0.20 \\
\hline & 12 & $12.21 \pm 0.08$ & 0.66 & $12.22 \pm 0.12$ & 0.98 \\
\hline & 25 & $25.07 \pm 0.05$ & 0.20 & $25.05 \pm 0.11$ & 0.44 \\
\hline & 50 & $49.84 \pm 0.04$ & 0.08 & $49.90 \pm 0.02$ & 0.04 \\
\hline & 100 & $99.64 \pm 0.14$ & 0.14 & $99.39 \pm 0.43$ & 0.43 \\
\hline & 200 & $199.68 \pm 0.44$ & 0.22 & $200.34 \pm 0.19$ & 0.09 \\
\hline & 300 & $300.33 \pm 0.33$ & 0.11 & $299.97 \pm 0.19$ & 0.06 \\
\hline \multirow{7}{*}{ ATP } & 10 & $9.78 \pm 0.02$ & 0.20 & $9.80 \pm 0.08$ & 0.82 \\
\hline & 12 & $11.84 \pm 0.06$ & 0.51 & $11.89 \pm 0.20$ & 1.68 \\
\hline & 25 & $25.12 \pm 0.06$ & 0.24 & $25.17 \pm 0.03$ & 0.12 \\
\hline & 50 & $50.10 \pm 0.02$ & 0.04 & $50.14 \pm 0.13$ & 0.26 \\
\hline & 100 & $100.07 \pm 0.14$ & 0.14 & $99.85 \pm 0.14$ & 0.14 \\
\hline & 200 & $200.40 \pm 0.12$ & 0.06 & $200.39 \pm 0.19$ & 0.09 \\
\hline & 300 & $299.70 \pm 0.11$ & 0.04 & $299.76 \pm 0.11$ & 0.04 \\
\hline \multirow{7}{*}{$\mathrm{ADN}$} & 10 & $10.19 \pm 0.05$ & 0.49 & $10.27 \pm 0.12$ & 1.17 \\
\hline & 12 & $12.22 \pm 0.07$ & 0.57 & $12.29 \pm 0.11$ & 0.90 \\
\hline & 25 & $25.07 \pm 0.01$ & 0.04 & $25.10 \pm 0.08$ & 0.32 \\
\hline & 50 & $49.78 \pm 0.01$ & 0.02 & $49.86 \pm 0.07$ & 0.14 \\
\hline & 100 & $99.54 \pm 0.07$ & 0.07 & $98.99 \pm 0.48$ & 0.48 \\
\hline & 200 & $200.10 \pm 0.27$ & 0.13 & $200.44 \pm 0.06$ & 0.03 \\
\hline & 300 & $300.10 \pm 0.20$ & 0.07 & $300.03 \pm 0.10$ & 0.03 \\
\hline
\end{tabular}

The test of extraction recovery showed high values, i.e., the recovery of ADN as an internal standard in all six samples was on average $95.21 \%$. Assuming that during the sample preparation and extraction procedure AMP, ADP, and ATP behave in the same way as $\mathrm{ADN}$ the high percentage of $\mathrm{ADN}$ extraction recovery can be the assurance of reliable determination and quantification of adenylates in the G. fossarum samples. G. fossarum samples stored at both $+4{ }^{\circ} \mathrm{C}$ and $-80^{\circ} \mathrm{C}$ for one week were stable as nucleotide degradation was within $10 \%$.

\subsection{Analysis of $G$. fossarum Samples}

\subsubsection{Influence of Homogenization Method on Adenylate Extraction}

To determine the most suitable and effective method for nucleotide extraction from amphipods, different homogenization approaches were employed: mechanical homogenization by Potter-Elvehjem homogenizer and a combination of mechanical and ultrasonic homogenization by Potter-Elvehjem homogenizer combined with sonication probe (Mini20, Bandelin, Germany). Although ultrasonic homogenization together with mechanical device effectively disrupted the G. fossarum exoskeleton, this approach resulted in a decreased yield of adenylates, most significant in ATP, when compared to a method where only mechanical disruption was applied (data not shown). Ultrasonication usually requires more sonication cycles, and it can cause a substantial increase in local temperature of the sample media. Hydrolysis of ATP, ADP, and AMP due to temperature increase was noted in several studies [30-32]. Recently, global molecular profiling was used for investigation of the effect of heating on small molecules such as triphosphate nucleotides (ATP, UTP, 
and GTP). ATP and ADP readily degraded within $60 \mathrm{~s}$ to AMP after heating at $150{ }^{\circ} \mathrm{C}$ [31]. Mechanical disruption using Potter-Elvehjem homogenizer was therefore chosen as more suitable method since it was completed within one minute which minimized temperature increase during sample disruption. Besides, during the homogenization procedure the sample tube must be kept in the ice-bath.

\subsubsection{Influence of $\mathrm{pH}$ on Adenylate Stability}

Nucleotide extraction by PCA is one of the most common methods for deproteinization and extraction of AMP, ADP, and ATP from various biological materials. However, the obtained acidic extract needs to be neutralized because of adenylate hydrolysis in extreme $\mathrm{pH}$ and additionally residual PCA can interfere with HPLC analysis [33]. Because of this, adequate volume of $\mathrm{KOH}$ needs to be added to the PCA to neutralize homogenization solution. A volume of $25 \mu \mathrm{L}$ of $25 \% \mathrm{KOH}$ was used for the neutralization of $200 \mu \mathrm{L} 0.5 \mathrm{M}$ PCA and $150 \mu \mathrm{L}$ of phosphate buffer as blank solution, which resulted in $\mathrm{pH}$ around 7 . However, when the volume of $25 \mu \mathrm{L}$ of $25 \% \mathrm{KOH}$ was added to test sample containing acid extract of $G$. fossarum, the final $\mathrm{pH}$ was around 11. Conclusively, amphipod cuticle composition can have a significant effect on homogenate $\mathrm{pH}$, possibly due to neutralization of PCA with $\mathrm{CaCO}_{3}$ from cuticle which consequentially increases alkalinity of the sample around $\mathrm{pH} 11$.

To avoid alkaline hydrolysis of adenylates, the volume of $25 \%$ of $\mathrm{KOH}$, added to acidic extract after homogenization, was reduced to $12 \mu \mathrm{L}$ and thus achieved approximately $\mathrm{pH}$ 9. Neutral $\mathrm{pH}$ around 7 was obtained with no $\mathrm{KOH}$ addition. Three tested neutralization solutions were analyzed in triplicates and the mean values of adenylate peak areas are shown in Figure 2. The RSD of peak areas was within 5\% (data not shown). It was apparent that peak area of ATP was the greatest at $\mathrm{pH}$ around 11 and declined with lower $\mathrm{pH}$, while AMP and ADP were stable in all three neutralization solutions (Figure 2). Further on, when chromatogram of $G$. fossarum homogenate $(\mathrm{pH} \approx 11)$ (Figure 3B) was compared to chromatogram of standard adenylate solutions (Figure $3 \mathrm{~A}$ ) it was evident that a higher $\mathrm{pH}$ of the test sample did not influence retention time and adenylate separation.

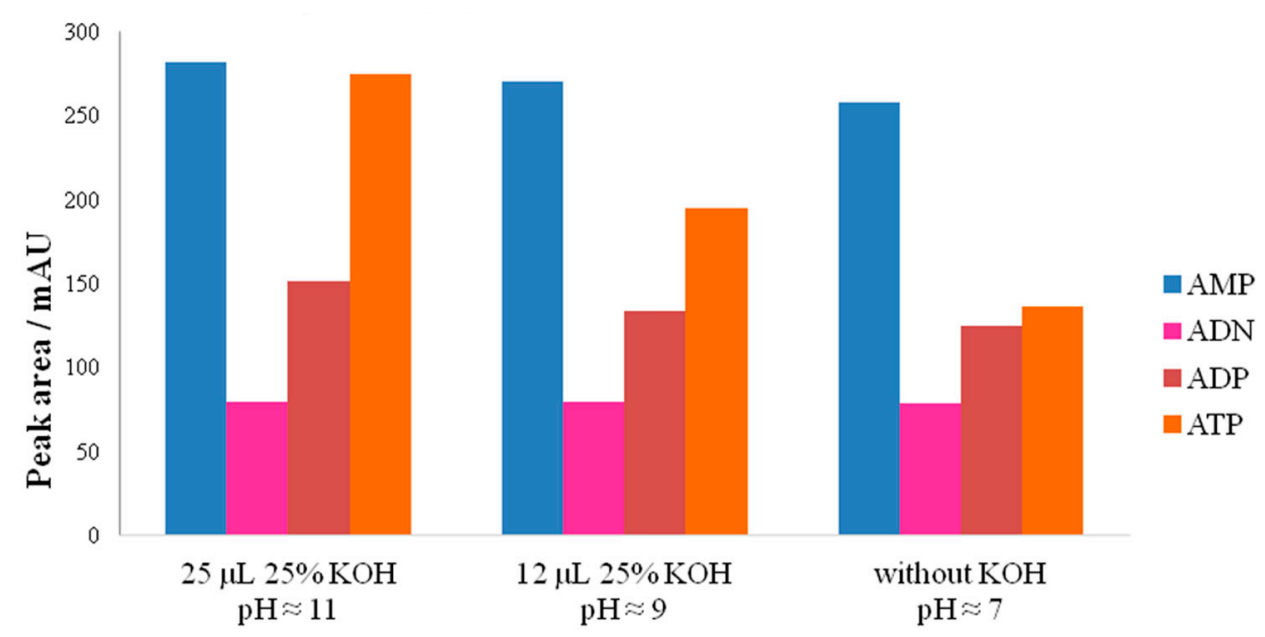

Figure 2. Column charts representing the mean peak areas of adenylates extracted with 0.5 M PCA from $G$. fossarum samples $(\mathrm{N}=6)$ after using three different neutralization solutions: neutralization with $25 \mu \mathrm{L}$ of $25 \% \mathrm{KOH}(\mathrm{pH} \approx 11$ ) and phosphate buffer; neutralization with $12 \mu \mathrm{L} 25 \% \mathrm{KOH}$ $(\mathrm{pH} \approx 9)$ and phosphate buffer; and with no phosphate buffer nor $\mathrm{KOH}$ added $(\mathrm{pH} \approx 7)$. 


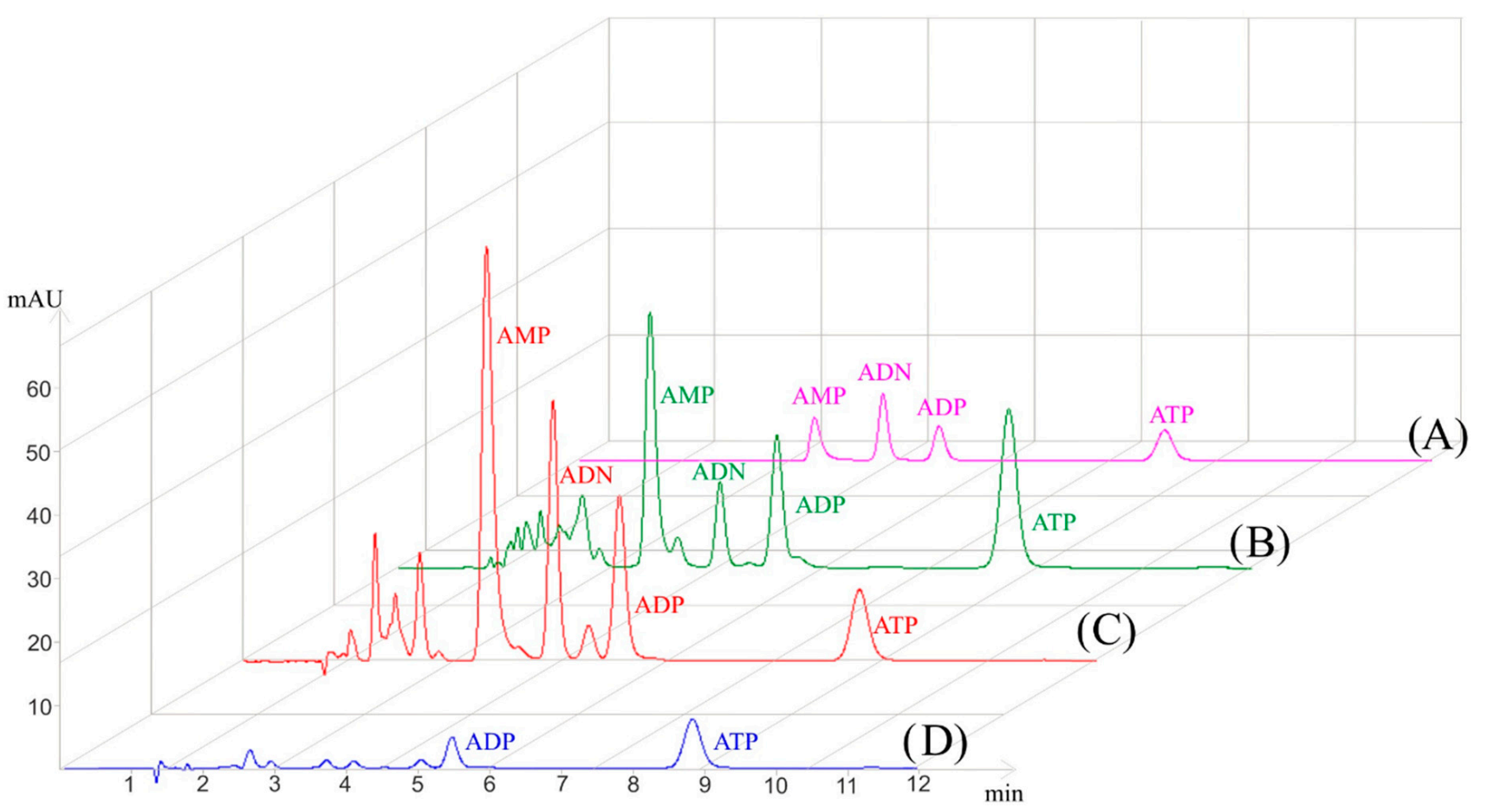

Figure 3. HPLC chromatograms of adenylate standards (A) and adenylates extracted from G. fossarum samples (B-D). (A) standards AMP, ADN, ADP, and ATP in the concentration of $25 \mu \mathrm{M}$; (B) G. fossarum homogenate with $\mathrm{pH}$ around 11; (C) fraction 1 of G. fossarum sample enriched on AssayMap Bravo platform; (D) fraction 2 of G. fossarum sample enriched on AssayMap where no AMP and ADN were eluted. For chromatographic separation conditions see Section 2.4.

It is also worth noting that one-week stability test of G. fossarum samples at $\mathrm{pH}$ around 11 at $+4{ }^{\circ} \mathrm{C}$ and $-80^{\circ} \mathrm{C}$ did not indicate significant hydrolysis of adenylates (see Section 3.1).

\subsection{Improved Sensitivity with PP $\mu S P E$}

Biological samples often contain impurities derived from biological molecules (e.g., lipids and proteins) or inorganic material (e.g., exoskeleton) that can interfere while measuring molecules of interest, especially if the analytes are present at low levels. Considering the different polarity of AMP, ADP, and ATP and basic nature of named molecules, separation and purification are quite challenging. A previously published method for SPE of nucleotides using StrataX [16] did not yield good results in terms of nucleotide ratios (data not shown); thus, a boronate affinity chromatography was employed for separation and enrichment of tested nucleotides. Boronate ligand is highly specific for cis-diol containing molecules therefore it interacts with AMP, ADP, ATP, and ADN through cis-diols at the ribose molecule [34]. Implementation of boronate affinity chromatography into the automated liquid handling platform protocol required minimal sample volume $(<100 \mu \mathrm{L})$ and enabled processing of multiple samples simultaneously. The highest yield was obtained when adenylates were eluted in two fractions. The first fraction, eluted in acetic acid, contained AMP, ADN, ADP, and ATP while ADP and ATP were eluted in the second fraction with sodium acetate (Figure 3C,D). Besides improving sensitivity, this method could enable complementation to liquid chromatography-mass spectrometry (LC-MS) due to sample purification and replacement of phosphate buffers used in the sample preparation procedure for more LC-MS friendly buffers.

\subsection{Application of AEC to Environmental Issues}

Pollution, temperature changes, watercourse regulation, or other disturbances can cause stress in aquatic organisms and therefore influence the available metabolic energy. Thus, determining the stress status of an organism is crucial for understanding the impact of environmental stressors, both natural and anthropogenic. AEC has been used as a 
physiological biomarker for environmental change, such as pollution [18] or hypoxia [35]. Reproductive cycle, growth, and food availability could also influence the adenylate pool $[9,13,36,37]$. In this study, the concentrations of adenylates (AMP, ADP, and ATP) in six composite samples of $\mathrm{G}$. fossarum $(\mathrm{N}=6)$ were determined by IP-RP-HPLC analysis and AEC was calculated according to equation (1). The highest average value was recorded for AMP $(1.99 \mu \mathrm{mol} / \mathrm{g}$ wet tissue); the ATP average value $(0.49 \mu \mathrm{mol} / \mathrm{g}$ wet tissue $)$ was four times less than AMP, while ADP had average value of $0.83 \mu \mathrm{mol} / \mathrm{g}$ wet tissue. AEC value in G. fossarum was around 0.3, which is an indication of metabolic stress in some organisms, possibly affected by environmental factors. However, a greater variety of species needs to be studied in order to evaluate whether a certain environment causes a decline in AEC among the overall population.

\section{Conclusions}

An efficient IP-RP-HPLC method was applied for sensitive quantification of adenine nucleotides in freshwater amphipod G. fossarum. The conducted isocratic method along with the entire extraction protocol uses only organic solvent-free solutions, making it environmentally friendly. Different adenylate extraction conditions were tested, and the most appropriate method was mechanical homogenization in PCA followed by alkalinization to $\mathrm{pH}$ around 11 with $\mathrm{KOH}$ under buffering conditions of phosphate buffer. The developed and validated IP-RP-HPLC method is linear, robust, and stable for each tested nucleotide. Furthermore, the sensitivity of the method was improved (at least ten times more sensitive than validated method) by PP $\mu$ SPE chromatography, which could enable measurements in samples with lower adenylate concentration making the analysis of only one organism possible. Validation of PP $\mu$ SPE method will be the next challenge in development of probably the most sensitive method for adenine nucleotides quantification. Finally, this method can be helpful for the determination of energy metabolism and AEC values for numerous aquatic organisms, e.g., for the first time AEC was estimated in amphipods due to method development that overcomes exoskeleton interferences, in realistic environmental conditions.

Author Contributions: Conceptualization, M.C. and M.E.; methodology, M.C., E.S., L.D., A.H. and Z.R.; validation, L.D., E.S. and Z.R.; formal analysis, Z.R., L.D. and E.S.; investigation, Z.R., E.S. and L.D.; resources, M.C., M.E. and Z.R.; writing-original draft preparation, Z.R., E.S. and L.D.; writing-review and editing, M.E., M.C. and S.G.; visualization, E.S., L.D., A.H. and Z.R.; supervision, M.E. and M.C.; project administration, M.C., M.E. and S.G.; funding acquisition, M.C. and M.E. All authors have read and agreed to the published version of the manuscript.

Funding: This research was funded by the Croatian Science Foundation, project number IP-2014-094255 and by European Regional Development Fund, KK.01.1.1.07.0023 Qua/Qua project.

Institutional Review Board Statement: Not applicable.

Informed Consent Statement: Not applicable.

Data Availability Statement: The original contributions presented in the study are included in the article; further inquiries can be directed to the corresponding author.

Acknowledgments: This work was supported by the Croatian Science Foundation and by the European Regional Development Fund. Institutional support of the Ministry of Science and Education of the Republic of Croatia is gratefully acknowledged.

Conflicts of Interest: The authors declare no conflict of interest. 


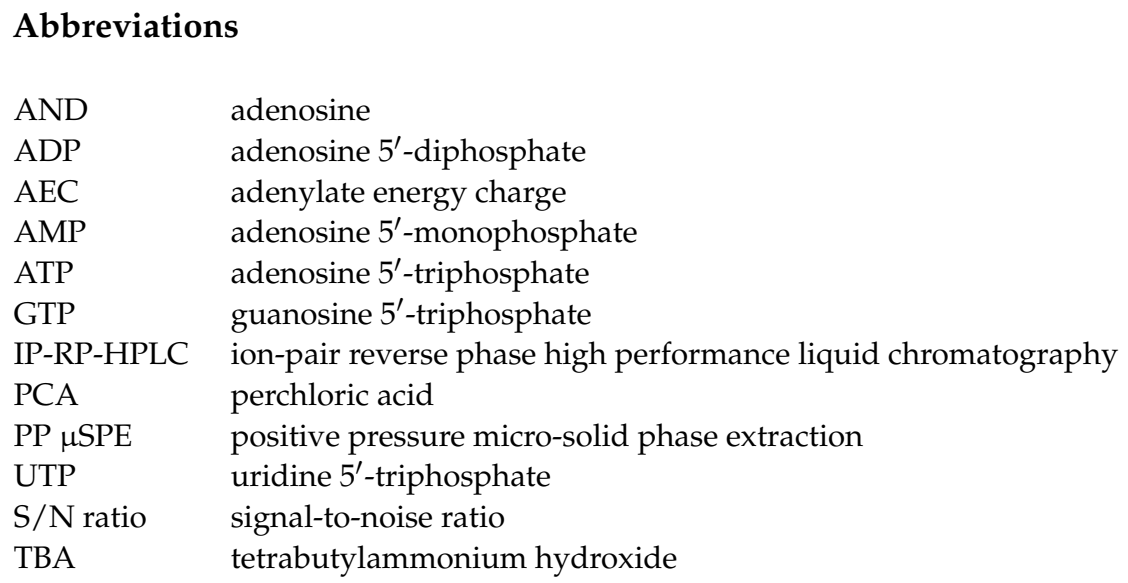

\section{References}

1. Friberg, N.; Bonada, N.; Bradley, D.C.; Dunbar, M.J.; Edwards, F.K.; Grey, J.; Hayes, R.B.; Hildrew, A.G.; Lamouroux, N.; Trimmer, M.; et al. Biomonitoring of human impacts in freshwater ecosystems: The good, the bad and the ugly. Adv. Ecol. Res. 2011, 44, 1-68. [CrossRef]

2. Fierro, P.; Valdovinos, C.; Vargas-Chacoff, L.; Bertrán, C.; Arismendi, I. Macroinvertebrates and fishes as bioindicators of stream water pollution. In Water Quality; Tutu, H., Ed.; IntechOpen: London, UK, 2017; pp. 24-38. [CrossRef]

3. Altermatt, F.; Alther, R.; Fišer, C.; Jokela, J.; Konec, M.; Küry, D.; Mächler, E.; Stucki, P.; Westram, A.M. Diversity and distribution of freshwater amphipod species in Switzerland (Crustacea: Amphipoda). PLoS ONE 2014, 9, e110328. [CrossRef]

4. Little, C.J.; Altermatt, F. Species turnover and invasion of dominant freshwater invertebrates alter biodiversity-ecosystem-function relationship. Ecol. Monogr. 2018, 88, 461-480. [CrossRef]

5. Bundschuh, M.; Zubrod, J.P.; Schulz, R. The functional and physiological status of Gammarus fossarum (Crustacea; Amphipoda) exposed to secondary treated wastewater. Environ. Pollut. 2011, 159, 244-249. [CrossRef] [PubMed]

6. Atkinson, D.E. Energy charge of adenylate pool as a regulatory parameter. Interaction with feedback modifiers. Biochemistry 1968, 7, 4030-4034. [CrossRef] [PubMed]

7. Prado, S.; Villamarín, A.; Ibarguren, I. Simultaneous determination of adenosine and related purines in tissues and hemolymph of mussel by HPLC. J. Liq. Chromatogr. Relat. Technol. 2013, 36, 470-485. [CrossRef]

8. Díaz Enrich, M.J.; Villamarín, J.A.; Ramos Martínez, J.I.; Ibarguren, I. Measurement of adenosine $3^{\prime}, 5^{\prime}$-cyclic monophosphate and guanosine $3^{\prime}, 5^{\prime}$-cyclic monophosphate in mussel (Mytilus galloprovincialis Lmk.) by high-performance liquid chromatography with diode array detection. Anal. Biochem. 2000, 285, 105-112. [CrossRef]

9. Blanco, S.L.; Suárez, M.P.; San Juan, F. Seasonal changes of nucleotides in mussel (Mytilus galloprovincialis) mantle tissue. Comp. Biochem. Physiol. B Biochem. Mol. Biol. 2006, 143, 384-390. [CrossRef] [PubMed]

10. Wang, Q.; Xue, C.; Li, Z.; Fu, X.; Xu, J.; Xue, Y. Changes in the contents of ATP and its related breakdown compounds in various tissues of oyster during frozen storage. J. Ocean. Univ. China 2007, 6, 407-412. [CrossRef]

11. Woll, A.K.; Bakke, S. Stress and mortality in the supply chain of live scallops Pecten maximus L., from scuba diver to market. Aquac. Res. 2017, 48, 594-607. [CrossRef]

12. Anacleto, P.; Maulvault, A.L.; Barrento, S.; Mendes, R.; Nunes, M.L.; Rosa, R.; Marques, A. Physiological responses to depuration and transport of native and exotic clams at different temperatures. Aquaculture 2013, 408-409, 136-146. [CrossRef]

13. Schäfer, S.; Abele, D.; Weihe, E.; Köhler, A. Sex-specific biochemical and histological differences in gonads of sea urchins (Psammechinus miliaris) and their response to phenanthrene exposure. Mar. Environ. Res. 2011, 71, 70-78. [CrossRef] [PubMed]

14. Guida, L.; Walker, T.I.; Reina, R.D. The adenylate energy charge as a new and useful indicator of capture stress in chondrichthyans. J. Comp. Physiol. B 2016, 186, 193-204. [CrossRef]

15. Napolitano, M.J.; Shain, D.H. Quantitating adenylate nucleotides in diverse organisms. J. Biochem. Biophys. Methods 2005, 63, 69-77. [CrossRef]

16. Czarnecka, J.; Cieślak, M.; Michał, K. Application of solid phase extraction and high-performance liquid chromatography to qualitative and quantitative analysis of nucleotides and nucleosides in human cerebrospinal fluid. J. Chromatogr. B 2005, 822, 85-90. [CrossRef]

17. Zur Nedden, S.; Eason, R.; Doney, A.S.; Frenguelli, B.G. An ion-pair reversed-phase HPLC method for determination of fresh tissue adenine nucleotides avoiding freeze-thaw degradation of ATP. Anal. Biochem. 2009, 388, 108-114. [CrossRef] [PubMed]

18. Schill, R.O.; Köhler, H.R. Does the environment or the source of the population define stress status and energy supply in the freshwater amphipod, Gammarus fossarum? Ecotoxicology 2004, 13, 683-695. [CrossRef]

19. Moal, J.; Le Coz, J.R.; Samain, J.F.; Daniel, J.Y. Nucleotides in bivalves: Extraction and analysis by high-performance liquid chromatography (HPLC). Comp. Biochem. Physiol. B 1989, 93, 307-316. [CrossRef]

20. Khlyntseva, S.V.; Bazel', Y.R.; Vishnikin, A.B.; Andruch, V. Methods for the determination of adenosine triphosphate and other adenine nucleotides. J. Anal. Chem. 2009, 64, 657-673. [CrossRef] 
21. Ribeiro, C.; Esteves da Silva, J.C. Kinetics of inhibition of firefly luciferase by oxyluciferin and dehydroluciferyl-adenylate. Photochem. Photobiol. Sci. 2008, 7, 1085-1090. [CrossRef]

22. Wang, L.; Li, Y.; Guo, R.; Li, S.; Chang, A.; Zhu, Z.; Tu, P. Optimized bioluminescence analysis of adenosine triphosphate (ATP) released by platelets and its application in the high throughput screening of platelet inhibitors. PLoS ONE 2019, 14, e0223096. [CrossRef]

23. Aragon-Martinez, O.H.; Galicia, O.; Isiordia-Espinoza, M.A.; Martinez-Morales, F. A novel method for measuring the ATP-related compounds in human erythrocytes. Tohoku J. Exp. Med. 2014, 233, 205-214. [CrossRef] [PubMed]

24. Logotheti, M.; Theochari, K.; Kostakis, M.; Pasias, I.N.; Thomaidis, S. Development and validation of a HILIC-UV method for the determination of nucleotides in fish samples. Food Chem. 2018, 248, 70-77. [CrossRef] [PubMed]

25. Dudley, E.; Bond, A.E. Proteomics in Biomedicine and Pharmacology. In Advances in Protein Chemistry and Structural Biology; Donev, R., Ed.; Academic Press: Cambridge, MA, USA, 2014; Volume 95, pp. 25-69.

26. Mora, L.; Hernández-Cázares, A.S.; Aristoy, M.C.; Toldrá, F. Hydrophilic interaction chromatographic determination of adenosine triphosphate and its metabolites. Food Chem. 2010, 123, 1282-1288. [CrossRef]

27. Furusawa, N. Organic solvent-free and simple method for determining cyromazine and its metabolite, melamine, in cow's milk. J. Anal. Sci. Meth. Instrum. 2012, 2, 68-73. [CrossRef]

28. Monasterio, R.P.; Londonio, J.A.; Farias, S.S.; Smichowski, P.; Wuilloud, R.G. Organic solvent-free reversed-phase ion-pairing liquid chromatography coupled to atomic fluorescence spectrometry for organoarsenic species determination in several matrices. J. Agric. Food Chem. 2011, 59, 3566-3574. [CrossRef]

29. Robles-Romo, A.; Arjona, O.; Racotta, I.S. Influence of sampling, storage, processing and optimal experimental conditions on adenylate energy charge in penaeid shrimp. Arch. Biol. Sci. 2014, 66, 651-666. [CrossRef]

30. Wei, H.; Tian, Y.; Lin, Y.; Maeda, H.; Yamashita, T.; Yu, K.; Takaki, K.; Yuan, C. Condition-dependent adenosine monophosphate decomposition pathways in striated adductor muscle from Japanese scallop (Patinopecten yessoensis). J. Food Sci. 2020, 85, 1462-1469. [CrossRef]

31. Fang, M.; Ivanisevic, J.; Benton, H.P.; Johnson, C.H.; Patti, G.J.; Hoang, L.T.; Uritboonthai, W.; Kurczy, M.E.; Siuzdak, G. Thermal degradation of small molecules: A global metabolomic investigation. Anal. Chem. 2015, 87, 10935-10941. [CrossRef]

32. Alberty, R.A. Thermodynamics of the hydrolysis of adenosine triphosphate as a function of temperature, $\mathrm{pH}, \mathrm{pMg}$, and ionic strength. J. Phys. Chem. B 2003, 107, 12324-12330. [CrossRef]

33. Simão, A.M.; Bolean, M.; Hoylaerts, M.F.; Millán, J.L.; Ciancaglini, P. Effects of pH on the production of phosphate and pyrophosphate by matrix vesicles' biomimetics. Calcif. Tissue Int. 2013, 93, 222-232. [CrossRef]

34. Liu, X.C.; Scouten, W.H. Boronate affinity chromatography. Methods Mol. Biol. 2000, 147, 119-128. [CrossRef] [PubMed]

35. Le Moullac, G.; Quéau, I.; Le Souchu, P.; Pouvreau, S.; Moal, J.; Le Coz, J.R.; Samain, J.F. Metabolic adjustments in the oyster Crassostrea gigas according to oxygen level and temperature. Mar. Biol. Res. 2007, 3, 357-366. [CrossRef]

36. Louis, F.; Rocher, B.; Barjhoux, I.; Bultelle, F.; Dedourge-Geffard, O.; Gaillet, V.; Bonnard, I.; Delahaut, L.; Pain-Devin, S.; Geffard, A.; et al. Seasonal monitoring of cellular energy metabolism in a sentinel species, Dreissena polymorpha (bivalve): Effect of global change? Sci. Total. Environ. 2020, 725, 138450. [CrossRef] [PubMed]

37. Delaporte, M.; Soudant, P.; Lambert, C.; Moal, J.; Pouvreau, S.; Samain, J.F. Impact of food availability on energy storage and defense related hemocyte parameters of the Pacific oyster Crassostrea gigas during an experimental reproductive cycle. Aquaculture 2006, 254, 571-582. [CrossRef] 